ISSN 1991- 8690

website :http:// jsci.utq.edu.iq

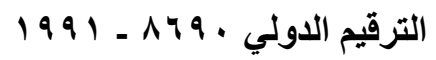

Email: utjsci@utq.edu.iq

\title{
SYNTHESIS AND CHARACTERIZAITION OF BISCYCLIC $\beta$ - LACTAMS AS BLOOD CHOLESTROL INHIBITORS
}

\author{
Wisam Obaid Salman \\ Mahmood Shakir Magtoof \\ Chemistry Dept_Science College Thiqar university_Thiqar_Nashyria,Iraq
}

\section{$\underline{\text { Abstract }}$}

This study is concerned with the synthesis and characterization of the 3-(4-chlorophenyl) bicyclic azetidin -2-one 3a. This compound 3a was prepared by reacting 3-(4-chlorophenyl) acetic acid with the appropriate Schiff's base $2 \mathbf{a}$ in the presence of triethylamine with phosphorusoxychloride in dry dichloromethane under nitrogen atmosphere at $-10^{\circ} \mathrm{C}$. The active acid chloride reacts with triethylamine to generate corresponding ketene in situ which further reacts with Schiff's base to furnish corresponding 3-(4-chloroPhenyl)bicyclic azetidin 2-ones 3a.And it was a study of the activity biological to compound $3 \mathrm{a}$ to inhibition of cholesterol in the blood of some laboratory animals. Key word : $\beta$ - LACTAMS , [2+2] CYCLOADDITION , 3-(4-CHLOROPHENYL)

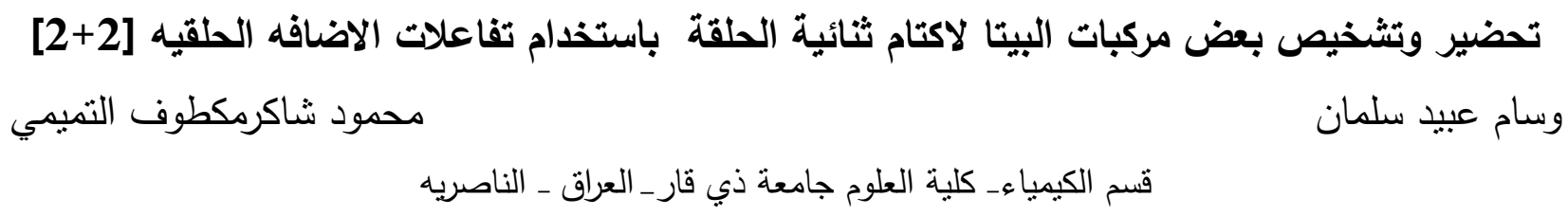

الملخص

\section{Introduction}

The first synthesis of a $\beta$-lactam was accomplished in 1907, when Staudinger discovered that ketenes and imines could undergo [2+2] cycloadditions to yield the $\beta$-lactam ring Figure $1 .^{1}$ This discovery was made long before the biological activity and therapeutic value of the $\beta$-lactam moiety was appreciated.

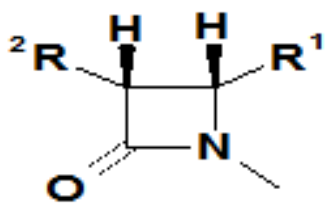

Figure 1

This situation changed with the dawn of the antibiotic age, when the synthesis and especially the enantioselective synthesis, of the $\beta$-lactam skeleton became prized. In pursuit of this goal, number of methods utilizing chiral auxiliaries were developed. ${ }^{2,3,4,5}$ While many of these auxiliarybased methods successfully produce enantiomerically enriched $\quad \beta$-lactams, suffer from requiring stoichiometric amounts of chiral starting materials, which are often very expensive. Recently ${ }^{6}$, in an effort to decrease the amount of chiral substance needed for effective enantioselective synthesis, several catalytic asymmetric routes to $\beta$-lactams have been developed. Sir Alexander Fleming discovered penicillin Figure 2 in 1929.7 Following the demonstration of the chemotherapeutic properties of penicillin, a search for an antibiotic producing organism was made by Professor Brotzu 8 in Sardinia .He examined the microbial flora of the seawater near a sewage outlet ,supposing that the process of self-purification of water 
might be due to bacteria lantagonism. He reported the discovery of cephalosporin Figure 3 which produced antibacterial material that has activity against certain Gram-positive as well as Gram-negative organisms. Brotzu believed that his results offered hopeful prospects, but he concluded that the isolation of the active material will be beyond his resource and he expressed hope, at the end of his publication that the work would be taken up elsewhere. The experiments with the Sardinian's cephalosporins were carried out at Oxford University labrotories and proved to contain an acidic antibiotic which was readily extractable by in organic solvents. 9

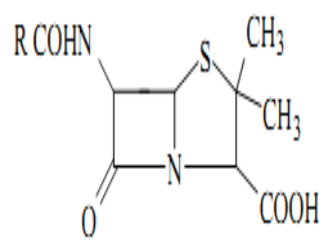

Figure 2

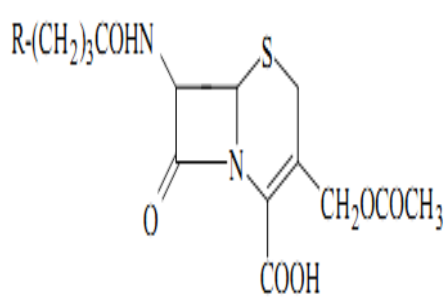

Figure 3
The synthesis of heterocyclic compounds has always drawn the attention of chemists over the years mainly because of their important biological properties. One such heterocyclic, 2-Azetidinone, a $\beta$-lactam four member compound involved in research which is aimed to evaluate new products that possess interesting biological activities. 2Azetidinone compounds reported for their antimicrobial and antifungal activities in resent past ${ }^{10}$. Most of the researches up to early 90s focused on synthesis of 2-azetidinones and study of their antibacterial property. In recent years ${ }^{11-16}$, renewed interest has been focused on the synthesis and modification of $\beta$-lactam ring to obtain compounds with diverse pharmacological activities like cholesterol absorption inhibitory activity, human tryptase, thrombin and chymase inhibitory activity, vasopressin V1a antagonist activity, antidiabetic, anti-inflammatory, antiparkinsonian and anti-HIV activity. They are also found to be a potent inhibitor of serine protease, human leukocyte elastase and human cytomegalovirus protease enzyme ${ }^{17-20}$, and are effective on central nervous system; in recent past these derivatives are also found to be moderately active against several types of cancer ${ }^{21}$. The biological activity of the $\beta$-lactam skeleton is generally believed to be associated with the chemical reactivity of their $\beta$-lactam ring and on the substituents especially at nitrogen of the 2azetidinone ring. The oxo group at 2 nd position i.e. 2-azetidinone is important for the activity whereas the substituents at the $\mathrm{N}-1, \mathrm{C}-3$ and C-4 position may be varied. Atherosclerotic coronary heart disease (CHD) has been the major cause of death and cardiovascular morbidity in the world ${ }^{22}$. The prominent risk factor associated with CHD was the elevation of serum cholesterol levels ${ }^{23}$.Well established clinical treatment for CHD has focused on life style changes and the reduction of serum cholesterol. These reductions have been shown to correlate strongly with the decrease of CHD mortality and the reversal of therosclerosis as evidenced by the regression of occlusion of coronary arteries $^{24}$.

\section{Results and discussion}

Taking a lead from earlier studies, 25 it was considered to utilize ketene-imine cyclization in the presence of triethylamine furnishing $\mathrm{C} 3-\mathrm{C} 4$ bond of $\beta$-lactam as key step for the synthesis of $1,1^{\prime}-(1,4-$ phenylene)bis(3-(4-chlorophenyl)-4-(2-hydroxy-3methoxyphenyl)azetidin-2-one) $\beta$-lactam $3 \mathrm{a}$ (figure 4).

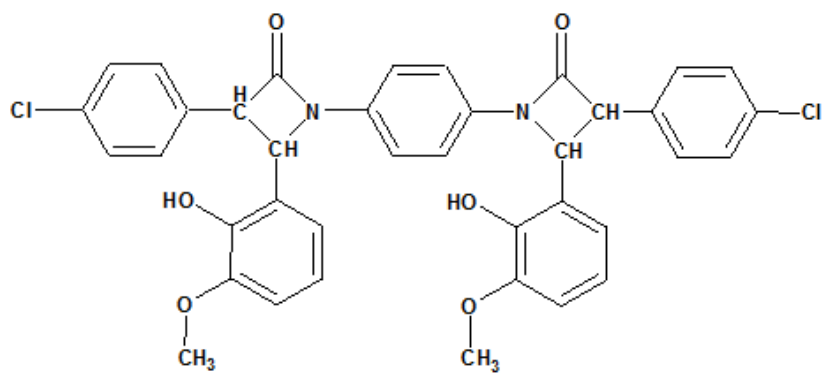

Scheme 1

The required various Schiff's base 2 a for the $\beta$ lactam formation $3 \mathrm{a}$ were prepared from reacting equimolar amounts of appropriate aromatic aldehyde(2-hydroxy-3-methoxybenzaldehyde) and aromatic amine (benzene-1,4-diamine) in refluxing ethanol. The structures of these imines 2a were confirmed on the basis of their spectral data (IR and NMR). The proposed reaction for their formations was shown as below in (scheme 3 ). 


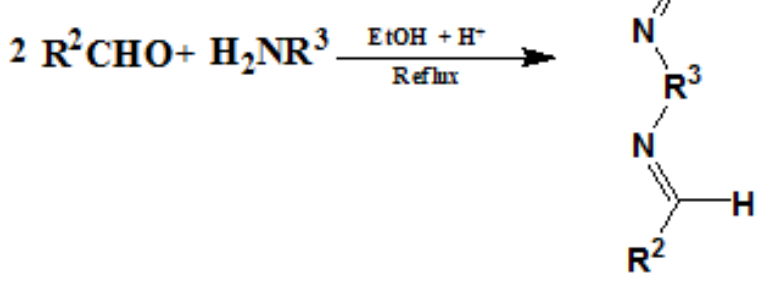

(2a)

Scheme 2

The active acid chloride formed from an appropriate acid with $\mathrm{POCl}_{3}$ was treated with triethylamine to give the corresponding ketene in situ which subsequently reacted with Schiff's base 2a to afford the corresponding $\beta$-lactam in moderate yields $(85 \%)$.The proposed reaction for their formations was shown as below in (scheme 3 ).
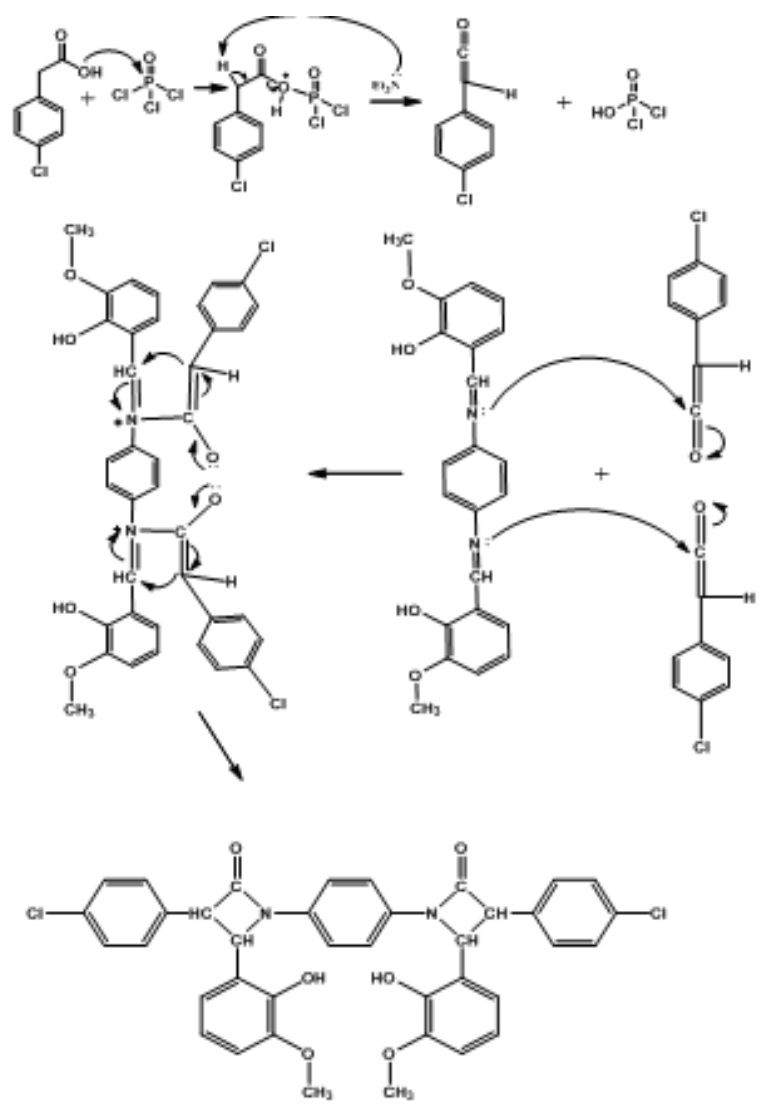

Scheme 3

\section{Effects of Compound (3a) on Serum Lipid} Profile

\section{Serum Cholesterol (TC) Concentration}

In the current study, the investigation of the protection role for (3a) against induced hyperlipidemia in mice, during 30 days of cholesterol intake, was done. Serum TC concentration was changed as shown in table (1) During 30 days, there was a significant increase in the serum concentration of $\mathrm{TC}$ in group (C) as compared with normal control group $(\mathrm{A})(\mathrm{P}<0.01)$. At these times, there was a significant reduction in the serum concentration of TC in groups (D) as compared with group $(\mathrm{C})(\mathrm{P}<0.01)$. On the other hand, a significant differences can be observed between(D) groups compared to control group (A). Whereas serum concentration of TC decrease a significant difference $(\mathrm{P}$ $<0.01$ ) in group (B) compared to control group (A) as show in scheme (4). These results are similar to the result of Bhusari, et al. (2011) that reported that betalactam ring to obtain compounds with diverse pharmacological activities like cholesterol absorption inhibitory activity ${ }^{26}$.

Table(1)

\begin{tabular}{||l|l|l|}
\hline Groups & $\begin{array}{l}\text { number } \\
\text { of } \\
\text { animals }\end{array}$ & $\begin{array}{l}\text { Cholesterol (mmol/1) } \\
\text { Mean } \pm \text { S.D }\end{array}$ \\
\hline Group A & 6 & $3.22 \pm 0.16^{c}$ \\
\hline Group B & 6 & $2.67 \pm 0.19^{\mathrm{b}}$ \\
\hline Group C & 6 & $4.28 \pm 0.37^{\mathrm{a}}$ \\
\hline Group D & 6 & $3.65 \pm 0.28^{\mathrm{b}}$ \\
\hline L.S.D & & 0.43 \\
\hline
\end{tabular}

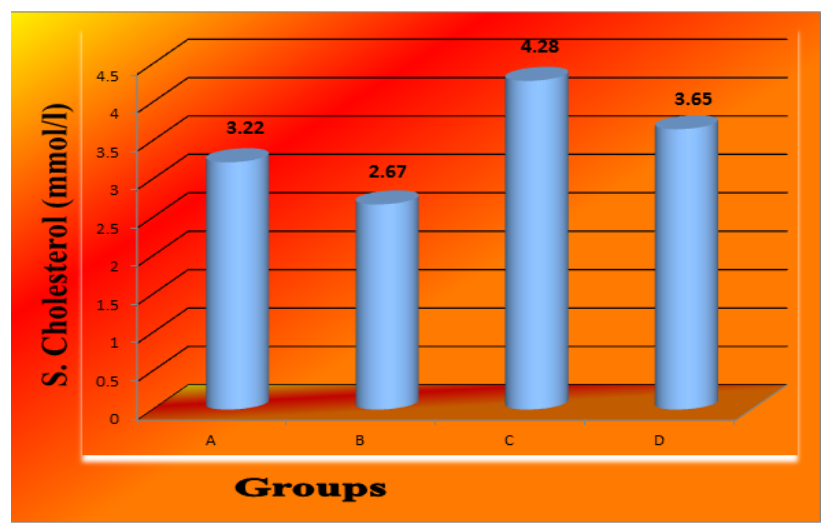

Scheme 4 
The structures of these azetidine-2-ones were established on the basis of spectral data, IR, Mass,${ }^{1} \mathbf{H}$ NMR, ${ }^{13} \mathbf{C}$ NMR spectra . IR spectrum of compound 3a showed strong stretching absorption band at $1768 \mathrm{~cm}^{-1}$ for $(\mathbf{C}=\mathbf{O})$ as shown Figure(1-1). The IR absorption frequencies of carbonyl groups $(\mathbf{C}=\mathbf{O})$ depended upon the nature of substituents at adjacent nitrogen atom.So the substitution of the phenyl ring by electron-donating groups such as hydroxy , methoxy or group lowered the absorption frequencies where as the substitution by an electronwithdrawing chloro group increased the absorption frequency.A similar trend in IR absorption frequency is reported by Lacroix ${ }^{27,28,29}$ et al.The ${ }^{\mathbf{1}} \mathbf{H}-\mathbf{N M R}$ of 3a showed four distinct doublets $\mathrm{C}_{3}-\mathrm{H} \delta(3.704-3.744)$ and $\mathrm{C}_{4}-\mathrm{H}$ $\delta(4.200-4.234) \quad$ The ${ }^{1} \mathrm{H}-\mathrm{NMR}$ spectrum of 3a showed singlet peak (equivalent protons ) for two methoxy groups at $\delta 3.204 \mathrm{ppm}\left(s, 6 \mathrm{H}, 2 \mathrm{CH}_{3}-\mathrm{O}\right)$, and showed broad peak at $4.504 \mathrm{ppm}$ for two(equivalent protons ) hydroxyl protons $(2 \mathrm{H}-\mathrm{OH})$. Finally , ${ }^{1} \mathrm{H}-\mathrm{NMR}$ spectrum of 3a showed aromatic protons integrated $18 \mathrm{H}$ at $\delta(6.542$ - 7.519 ) ppm shown in Figure (1-2) The ${ }^{13} \mathbf{C}$ NMR spectrum of the 3a showed resonance between $\delta 172.06$ 174.58 ppm which assigned to the carbon ${ }^{\mathbf{3 0 , 3 1 , 3 2}}$ group. The resonance at $\delta 174.06 \mathrm{ppm}$ was assigned to the carbonyl carbon atom, whereas the singlet at $\delta 153.30,141.98$, $141.69,140.73,140.57,129.08,128.33,122.54,117.39$ , $108.07 \mathrm{ppm}$ were belonged to the aromatic carbons .C4 and C-3 were appeared at $\delta 65.52$ and $58.70 \mathrm{ppm}$ respectively, whereas the resonance at $\delta 51.28 \mathrm{ppm}$ were assigned to the methoxy carbon atom respecteivly figure (1-3).The mass spectra of compound 3a, showed the molecular ion peak corresponding to the particular compound $\left[\mathrm{M}^{+} \cdot\right], \mathrm{m} / \mathrm{z}=680$. The fragmentation of $\mathbf{3 a}$ lead to ketene, isocyantes and imine . The fragmentation of 3a leading to the ketene $\mathrm{m} / \mathrm{z}=152$, and the corresponding isocyantes $\mathrm{m} / \mathrm{z}=160$ also the fragmentation of this compound 3a showed the imine peaks $\mathrm{m} / \mathrm{z}=376$.The fragmentation mechanism of compounds $\mathbf{3 a}$ is shown below $^{\mathbf{1 7 , 1 8}}$ (Schemes5) figure(1-4)

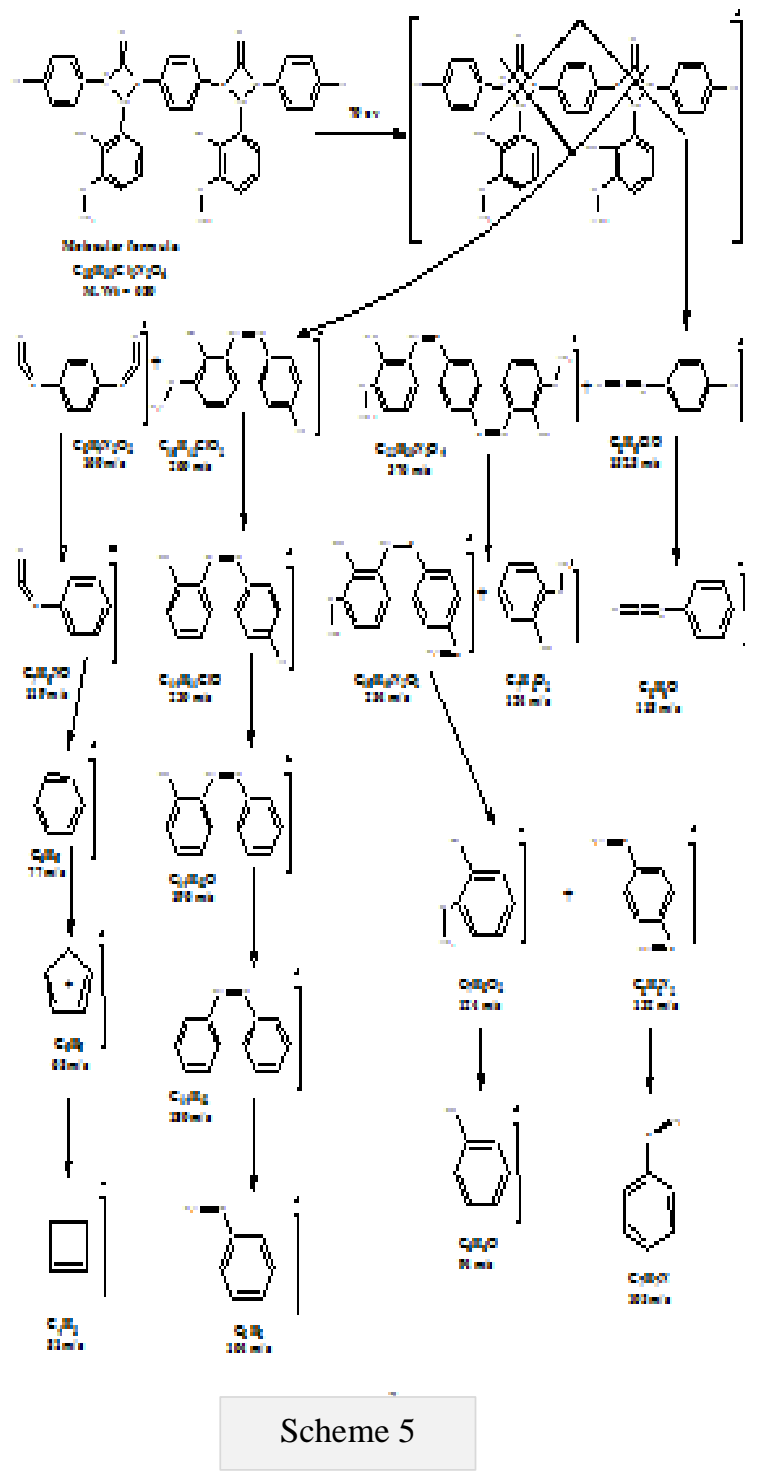

\section{The Experimental}

All solvents were distilled / dried prior to use.All solvent (3a) were dried over anhydrous sodium sulphate unless other wise specified. ${ }^{\mathbf{1 3}} \mathbf{C}$ NMR; ${ }^{\mathbf{1}} \mathbf{H N M R}$ Spectroscopy were recorded using Bruker DRX system AL $500(500 \mathrm{MHz})$. in the Department of Chemistry ,Sharif University, Tahran, Iran. Mass spectrum was recorded at $70 \mathrm{eV}$ using agalint technologes Spectrum 5973 in the Department of Chemistry,Tahran Uinversity, Tahran Iran . IR spectra were recorded, using shimadzu FT-IR affinity spectrophotometer in the Department of Chemistry, College of Science, Thi-Qar University, Iraq, as $\mathrm{KBr}$ disks. Only principal absorption bands of interest are reported and expressed in cm-1. 


\section{1 : Preparation of Schiff base $2 a^{33,34}$ \\ General Procedure}

A mixture of an appropriate aromatic amine (benzene-1,4-diamine) (0.01 mole) and an aromatic aldehyde(2-hydroxy-3-methoxybenzaldehyde) $\quad \mathbf{( 0 . 0 2}$ mole) in $25 \mathrm{ml}$ of absolute ethanol and one drop of glacial acetic acid was heated at $\left(70-80^{\circ} \mathrm{C}\right)$ for $30 \mathrm{~min}$ .The progress of the reaction was checked by TLC. After completion the solvent was evaporated then recrystallized from a suitable solvent by benzene .

\section{2 : Preparation of $\beta$-lactam 35,36}

\section{1,1'-(1,4-phenylene)bis(3-(4-chlorophenyl)-4-} (2-hydroxy-3-methoxyphenyl)azetidin-2-one (3a) .

To a suspension of 2-(4-chlorophenyl)acetic acid ( $0.34 \mathrm{~g}, 2$ mmole) , 6,6'- (1,4-phenylenebis(azan-1-yl-1ylidene))bis(methan-1-yl-1-ylidene)bis(2-

methoxyphenol) 2a $(0.376 \mathrm{~g}, 1 \mathrm{mmole})$ and triethylamine $(0.303 \mathrm{~g}, 6.0 \mathrm{mmole}, 0.42 \mathrm{~mL})$ in $40 \mathrm{~mL}$ of dry dichloromethane was added dropwise, under nitrogen atmosphere, a solution of $\mathrm{POCl}_{3}(0.3684 \mathrm{~g}, 2.4$ mmole, $0.22 \mathrm{~mL}$ ) in $20 \mathrm{~mL}$ dry dichloromethane with constant stirring at $-10^{\circ} \mathrm{C}$. The reactants were stirred overnight at room temperature. There after the contents were washed successively with $1 \mathrm{~N} \mathrm{HCl}$ $(20 \mathrm{~mL}), 5 \% \mathrm{NaHCO}_{3}(20 \mathrm{~mL})$ and brine $(20 \mathrm{~mL})$.The organic layer was separated and dried over anhydrous $\mathrm{Na}_{2} \mathrm{SO}_{4}$. The solvent was removed under vacuum and the crude product was column chromatagraphed over silica gel using 7:3 ethyl acetate/ hexane as eluent .Solvent evaporation furnished a pure $\beta$-lactam (3a).

\section{3 : Animals and Housing}

Twenty four healthy adult female mice weighing (25-35 g ) of 8 weeks old were used in the present study. Animals were housed in the animal house of Biology Dept. College of Science, Thi-Qar University. Experiments were achieved between August-2013 \& September-2013. Animals were housed in iron boxes bedded with wooden chips. During the experimental period six animals were kept in each box and they were housed under standard laboratory conditions $(12 \mathrm{~h}$ light:12h dark photoperiod (LD)at $22 \pm 2 \mathrm{C}^{\mathrm{o}}$ and relative humidity 45-55\%.37 Animals were fed on standard rat pellet and tap water Ad libitum. The standard pellet contains wheat $66.6 \%$, soya $25.6 \%$, and sun flower oil $4.4 \%$, lime stone $1.5 \%$, salt $0.63 \%$, methionine $0.158 \%$, choline chloride $0.062 \%$ and trace elements $0.05 \% .38$

\section{4 : Administration of Laboratory Animals:39}

Experimental animals were divided into four groups (6 mice in each group) upon the following designed:

- Group A: control (normal) that were treated with DMSO.

- Group B: Mice were treated with daily high cholesterol diet for 30 days .

- Group C: Mice were daily extract besides high cholesterol diet for 30 days.

- Group D: Mice were daily treated with 3a extract besides high cholesterol diet for 30 days.

(3.4mg of extract dissolved in $50 \mathrm{ml}$ of DMSO, and the rats were given daily oral $)^{40}$

\section{5: Method of Food Preparing (High Cholesterol Diet)41}

$50 \mathrm{~g}$ of cholesterol dissolved in $200 \mathrm{~g}$ of olive oil and heated in a water bath, and after soluble cholesterol in the oil were added to $1 \mathrm{~kg}$ of feed, then was cut into small pieces fit with the size of the holes in the lid iron to boxes, to facilitate the process taken up by mice .

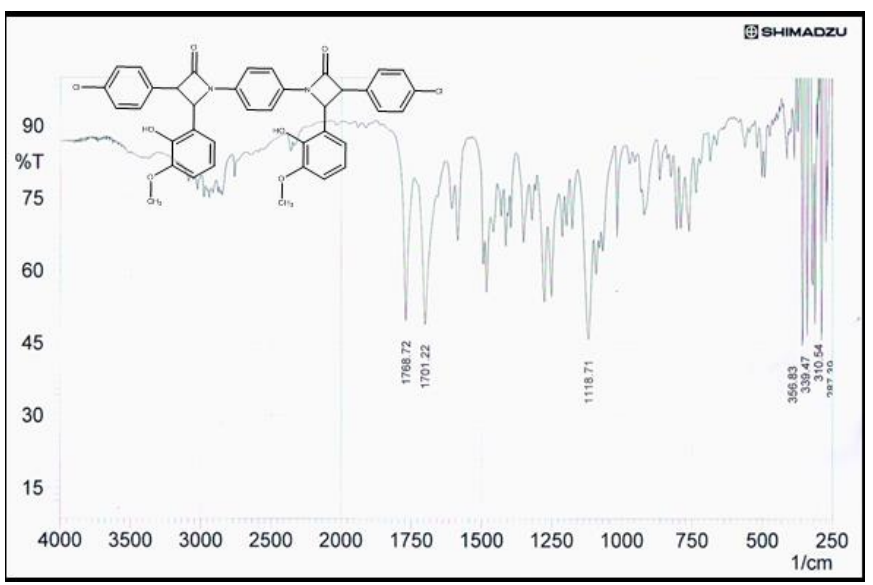

Figure (1-1) :FT-IR spectrum of $1,1^{\prime}-(1,4-$ phenylene)bis(3-(4-chlorophenyl)-4-(2-hydroxy-3methoxyphenyl)azetidin-2-one) (3a) 


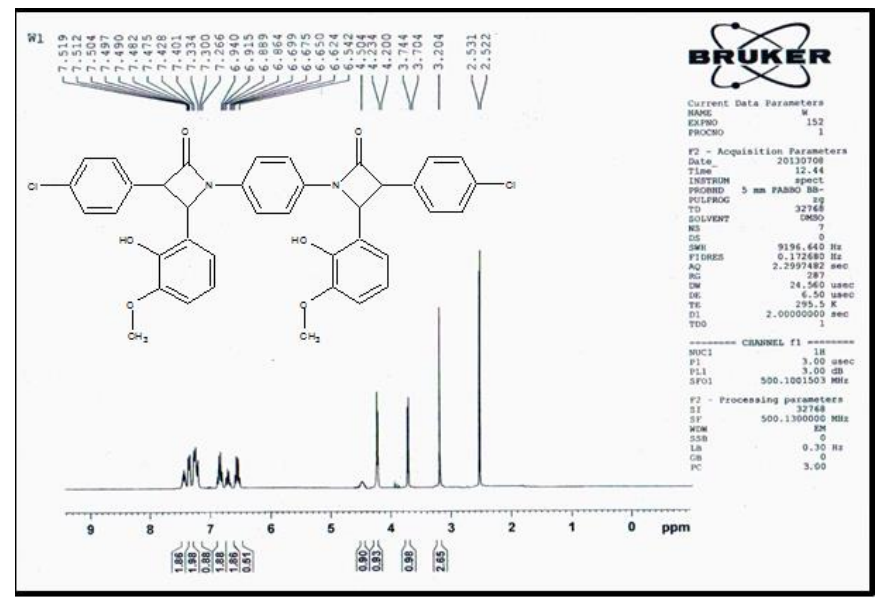

Figure (1-2) : ${ }^{1} \mathrm{H}$ NMR spectrum of 1,1'-(1,4phenylene)bis(3-(4-chlorophenyl)-4-(2-hydroxy-3methoxyphenyl)azetidin-2-one) (3a)

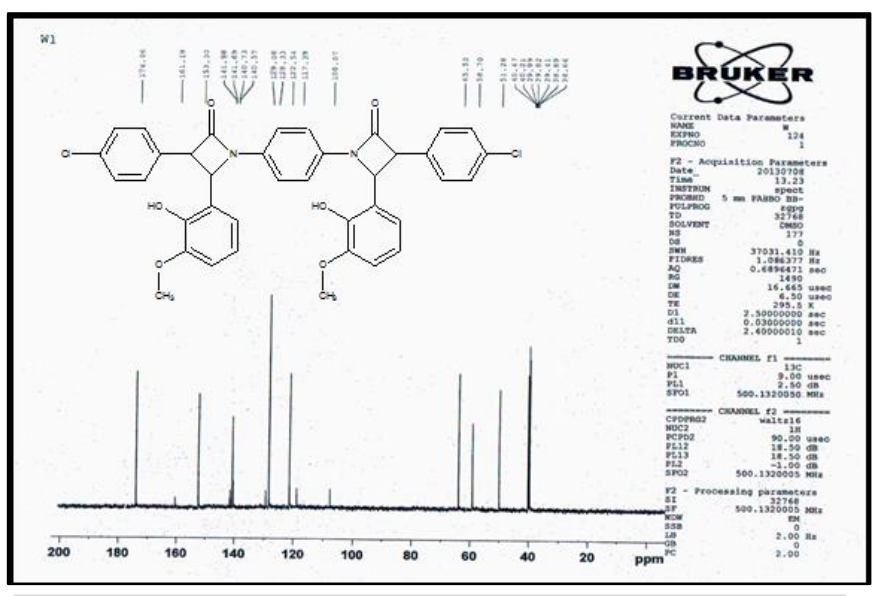

Figure (1-3) : ${ }^{13} \mathrm{C}$ NMR spectrum of 1,1'-(1,4phenylene)bis(3-(4-chlorophenyl)-4-(2-hydroxy-3methoxyphenyl)azetidin-2-one) (3a).

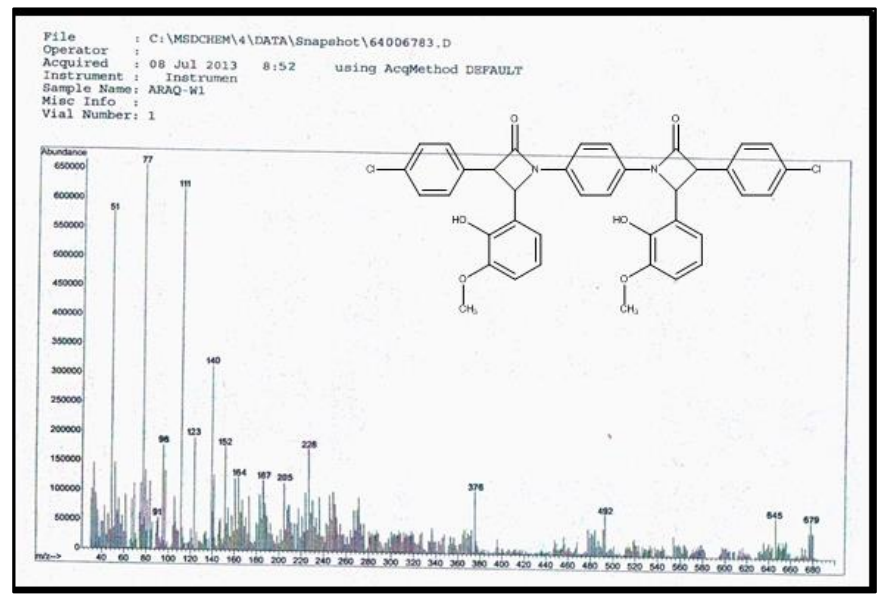

Figure (1-4) : Mass spectrum of 1,1'-(1,4phenylene)bis(3-(4-chlorophenyl)-4-(2-hydroxy-3methoxyphenyl)azetidin-2-one) (3a).

\section{References}

1- Staudinger, H; Liebigs Ann. Chem, 356, 51, 1907

2 - Palomo, C.; Aizpurua, J.M.; Ganboa, I.; Oiarbide, M. Eur. J. Org. Chem., 3223, 1999.

3 - Basak, A.; Ghosh, S.C.; Bhowmick, T.; Das, A.K.; Bertolasi, V. Tetrahedron Lett, 43, 5499.2002

4 - Natarajan, A.; Wang, K.; Ramamurthy. V.; Scheffer, J.R.; Patrick. B,Org. Lett., 4, 1443. 2002

5 - Hart, D.J.; Ha, D.C,Chem. Rev, 89, 1447. 1989

6 - Magriotis, P.A. Angew. Chem. Int. Ed, 40, 4377. 2001

7 - Fleming .A. Brit, J. Exp. Path , 10, 226,1929

8 - Brotzu G., Lavori tell'institus D'Igiene de cagilari, "Cephalosporin and

Penicillin", E. Flenz, 24, 1948

9 - Abraham E.P. and Newton G.G.F, Biochem. J., 79, 377. 1961

10 -Ceric H, Sindler-Kulyk H, Azetidinoneisothiazolidinones Stereoselective synthesis and antibacterial evaluation 18;3053-58, 2010

11- Burnett D.A; Caplen. M.A ; Davis HR and Burrrier REJW, J Med Chem. 37:1733-36 1994

12 - Bergman .M ; Morales.H; Mellars. L ; Kosoglou. $\mathrm{T} ; 12$ th International Symposium on drugs affecting lipid metabolism, Houston, TX, 7-10 .1995

13- Slusarchyk .W.A; Bolton .S.A ; Hartl KS and Huang .M.H , Med. Chem. Lett; 12-3235- 2002

14- Han .W.T; Trehan .A.K; Wright. J.K ; Federici. M.E ; Bioorg Med Chem. 8:1123-28; 1995

15 - Guillon .C.D; Koppe .A; Brownstein .M , Bioorg Med Chem.15:2054; 2007

16- Srivastava S.K; Srivastava .S, Srivastava .S,Ind Chem. 38B:183;1999.

17- Knight .W.B; Green .B.G; Chabin. R.M ; Gale .P, Biochemistry 31:8160.9. 1992

18- Firestone .R.A; Barker .P.L; Pisano .J.M ;Ashe .B.M,Tetrahedron;46:2255. 1990

19-Vergely. I; Laugha .P , J Mol Graph. 14:158-167. 1996

20- Singh.R , Micetich.R.G. IDrugs. 3; 512. 2000

21- Veinberg .G; Bokaldere.R; Dikovskaya .K , Heterocyclic Compounds-41:1494.1998

22-Iyer .S.P; Yao .X; Crona. J, Hoos .L.M; Grazian .M.P, Biochim Biophys Acta.;1772: 282-922005

23 - Ros .E,Atherosclerosis;151:357-79. 2000

24- Brown. G;Albers .J, Engl J Med;323:1289.1990

25- Enders, D.; Gries .G.,Synthesis 3508, 2005. 
26- Bhusari, K.P., Charbe, N. B. , Meherea, A.P, Warokar, A.S, Kakde.J.W; Mishra.A.P. INTERNATIONAL JOURNAL OF RESEARCH IN PHARMACY AND CHEMISTRY. 1(4). 2231-2781.2011.

27- . Lacroix.S;Pannecoucke .X; Outerquin .F. Paulmier .C, Eur. J. Org. Chem., 995,2002.

28-.Lacroix.S;Cheguillaume.A;Gerard.S, J.,Synthesis., 2483, 2003.

29- . Lacroix.S; Kiyota.H; Takai.T; Saitoh.M; Nakayama.O; Oritani.T;Kuwahara. S, Tetrahedron Lett., 45, 8191,2004.

30-Lacroix.S;Cheguillaume.A;Gerard.S,J. Synthesis, 2483-2486,2003 .

31.Dekimpe.N;Katritzky.A;Rees.C,ComprehensiveHete rocyclicChemistyperg amon,UK, ,2,507,1995 .

32.Kiyota,H.,Takai.T,Saitoh,M.,Nakayama,O.,Oritani,T .,and KuwaharA.S.,Tetr-ahedron Lett.,45,81918194,2004 .

33-Hello.K .M ,Iraqi .J .of Chem ., 24 , 266 , 2000 .

34- Krishnaswamy.D, Tetrahedron, 34 , 4567,2002.

35- Turos et al., E. , I Bioorg. Med. Chem., 13, 62896308. 2005.

36-Jarrahpour.A.A;Shekarriz.M, Molecules., 9, 29-38, 2004 .

37. Coskun.O;Ocakci.A;Bayraktaroglu. T; Kanter.M,Tohoku J. Exp. Med. 203:145-154. 2004

38. Krinke.G,J. The laboratory Rat. Academic press. A Harcourt Science and Technology company Sand Diego. 2000

39. Metwally.M; El-Gellal, A.M; El-Sawaisi, S.M,World applied sciences Journal. 6(12): 1634-1637. 2009

40. Smith.E;Hadidian.Z; Mason, M.M,Ann. New York Acad. Sci. 141: 969.1967

41. Cook.R. P; Thomson.R, J. exp. Physiol. 36:61. 1950 